RELACult - Revista Latino-Americana de Estudos em Cultura e Sociedade e-ISSN 2016/Atual: 2525-7870 | e-ISSN 2015/2016: 2447-018X

\title{
Processos criminais sobre ladrões de gado dentro do contexto de construção da justiça em Uruguaiana (1899 - 1904)
}

\author{
Los casos criminales de los ladrones de ganado en el contexto del empiezo \\ de la justicia en Uruguaiana (1899 - 1904)
}

Criminal cases on cattle rustlers in the justice building context in Uruguaiana (1899 - 1904)

\section{Lic. Marcelo Bahlis 1}

\begin{abstract}
Resumo
Este artigo aborda aspectos teórico metodológicos sobre processos criminais e são parte de uma reflexão que faço ao pesquisar o município de Uruguaiana, fronteira oeste do Rio Grande do Sul, entre 1899 e 1904. Busco analisar tais processos dentro do processo de construção do aparato burocrático do Estado Nacional. A partir dos processos judiciais autuados no artigo 330 da Constituição da República de 1890, referentes ao roubo de gado, encontrados no Arquivo Público do Estado do Rio Grande do Sul, traço uma narrativa sobre a metodologia de como tais processos foram manejados por mim na pesquisa histórica e por fim, tento encontrar relações entre o discurso da justiça e do Estado sobre práticas punitivas do roubo de gado na região e as transformações que estavam se dando na sociedade fronteiriça no fim do século XIX e início do século XX.
\end{abstract}

Palavras-Chave: Abigeato; Criminalidade; Fronteira; Historiografia; Processos Crime.

\section{Resumen}

Este artículo analiza los casos criminales en la ciudad de Uruguaiana, frontera oeste de Rio Grande do Sul, entre 1899 y 1904 y tiene como objetivo analizar estos procesos dentro del proceso de construcción del aparato burocrático del Estado Nacional. A partir de las demandas presentadas en el artículo 330 de la Constitución de 1890 República, por el robo de ganado, que se encuentra en el Archivo Público del Estado de Río Grande do Sul, busco trazar una narración sobre la metodología de cómo estos casos fueron manejados por mí en la investigación histórica y, finalmente, tratar de encontrar relaciones entre el discurso de la justicia y el estado de las prácticas punitivas de robo de ganado en la región y los cambios que se estaban recibiendo en la sociedad de frontera a finales del siglo XIX y principios del XX.

Palabras claves: Abigeo; Criminalidad; Frontera; Historiografia; Proceso Judicial.

\section{Abstract}

This article discusses the criminal cases in the city of Uruguaiana, western border of Rio Grande do Sul, between 1899 and 1904 and seeks to analyze such processes within the process of construction of the bureaucratic apparatus of the National State. From the lawsuits filed in the Article 330 of the Constitution of 1890 Republic, for the theft of cattle, found in the State Public Archives of Rio Grande do Sul, I seek to trace a narrative about the methodology of how such cases were handled by me in historical research and finally try to

\footnotetext{
${ }^{1}$ Licenciado em História; Universidade Federal do Rio Grande do Sul - UFRGS; Porto Alegre, Rio Grande do Sul, Brasil; bahlis@ @hotmail.com.
} 
find relationships between the discourse of justice and rule of punitive practices of cattle theft in the region and the changes that were getting in the border society in the late nineteenth century and early twentieth century.

Keywords: Border; Cattle Theft; Criminality; Historiography; Lawsuits.

\section{Introdução}

Este artigo faz parte de uma pesquisa maior em que estudo os significados dos furtos de gado no município de Uruguaiana na passagem do século XIX para o século XX. Este texto é um recorte sobre processos teórico metodológicos em que faço uma reflexão sobre como analisei os processos judiciais encontrados no Arquivo Público do Estado do Rio Grande do Sul. Entendo que o aparato burocrático judicial estabelecido pelo Estado não foi um processo unidirecional, guiado pelo centro da incipiente República até a fronteira. Analisando os processos e com base na historiografia percebi que as normas que começavam a se estabelecer guiadas por práticas capitalistas, foram sendo negociadas entre o poder do Estado e o poder local. Os processos me deram fortes indícios de que havia práticas pré capitalistas ainda acontecendo no município. Porém, percebo que o aparato burocrático da justiça começava a pautar as relações com base na propriedade privada, criminalizando formas consuetudinárias de relações sociais da fronteira.

\section{O crime na historiografia}

"A história dos dominados vêm à tona pela pena dos escrivães de polícia" (Reis, 1986, p.8). A história social a partir das décadas de 1970 e 1980 encontrou nos processos judiciais uma fonte sobre as narrativas da população das classes populares frente aos delegados de polícia e juízes. Os historiadores começaram a problematizar as falas transcritas nos tribunais de justiça pelos marginais da sociedade que não eram privilegiados pela historiografia tradicional.Nestas falas transcritas, pôde-se ter acessos a informações como os locais de moradia e como se portavam os excluídos da história perante a justiça institucional. As falas transcritas em terceira pessoa, mesmo com a possível descaracterização que uma transcrição possa gerar, já que possui filtros profissionais e morais do escrivão, têm o poder de captar as categorias da lei, valores e estratégias das partes em disputa que desejam culpar ou inocentar determinado agente social. Considera-se portanto que o documento judicial é um produto social, profissional e político. (MAUCH, 2013, p.25).

Não posso deixar de pensar que o objetivo principal da produção das fontes judiciais era ser um relato linear de diferentes partes que defendiam seu ponto de vista conforme as condições que a justiça impunha aos réus, vítimas e testemunhas. Mas para o historiador, 
além do relato linear, as diferentes versões da mesma pessoa, referências à cor, gênero e condição social são fatores que devem ser comparados. "Não cabe ao historiador ir atrás dos culpados e inocentes, sua investigação é outra". (MAUCH, 2013, p.22). Ao perceber as condições em que a fonte histórica foi gerada, e não tomar os escritos dos autos de forma ingênua, o historiador permite que uma nova análise seja feita daqueles documentos.

Sydney Chalhoub defende que deve-se pensar nas contradições e incoerências que constituem tal fonte. Segundo o autor, "a verdade para o historiador, os significados do tempo estudado, devem ser buscados nas relações que se repetem sistematicamente nos processos crime. A partir disso, ou seja, das versões conflitantes, é possível construir explicações sobre o social dentro do contexto histórico". (CHALHOUB, 1986, p.23). A contribuição do autor gerou trabalhos que trouxeram para a pesquisa histórica questões como o controle social e as práticas cotidianas das classes populares, de modo que sua obra influenciou inúmeros historiadores com sua utilização dos processos crime.

Ao encontro deste modo de pensar, Bóris Fausto, escreve que um caso não se encerra como caso individual, mas abre caminho para muitas percepções. (FAUSTO, 1884, p.9). Os trabalhos destes autores possibilitaram que os historiadores que analisam a construção do período republicano encontrassem nos autos judiciais uma fonte preciosa de pesquisa. Tal fato possibilitou que novas abordagens e novos atores sociais surgissem para os livros de história. Bretas mostra que estes estudos focalizaram suas análises sobre a produção do desvio, refletindo sobre a produção do discurso formador das chamadas "classes perigosas". Segundo esta corrente na historiografia, a criação do discurso que vincula as classes baixas ligados às classes perigosas seria utilizado como estratégia de um capitalismo em formação, que visava controlar grupos sociais para disciplinar corpos e mentalidades. (BRETAS, 1991, p.56).

Ressalto que a justiça criminal, como relata Bretas, oferece pistas para se compreender como as camadas baixas se comportavam frente aos funcionários da justiça. Portanto, com estas fontes pode-se encontrar os relatos que vítimas, réus e testemunhas falaram buscando legitimar sua versão do ocorrido. Karl Monsma escreve que a justiça criminal não só julga como se preocupa com a motivação e intenção dos envolvidos. De tal modo, também é possível encontrar nos arquivos da justiça, as narrativas de homens e mulheres que buscavam obter apoio em sua versão, mas que também diziam a respeito de suas vidas e suas relações sociais. (MONSMA, 2005, p.164).

Outro ponto importante diz respeito ao que Bóris Fausto escreve: quando se pensa nos arquivos judiciais, deve-se levar em conta dois acontecimentos: o fato ocorrido e a atuação do aparelho repressivo. A transformação de "atos em autos" e de "fatos em versões": é 
importante entender essa diferença. (FAUSTO, 1984. pp.21-22).

Nos autos que analiso, houve um crime, que primeiramente passou pelas mãos da polícia, que abriu o inquérito. Nestes, cuja transcrição geralmente aparece nos processos judiciais, os depoimentos estão transcritos sem tantos filtros, correspondendo a transcrições com gírias e mais próximos da linguagem dos depoentes. Os policiais muitas vezes possuíam relações com as classes populares, de modo que podia haver tanto empatias como formas de micro poder e hierarquias locais. Já na parte dos depoimentos nos julgamentos, as falas aparecem mais enquadradas na linguagem dos processos, sem gírias e com um vocabulário que poderia ter sido transcrito com menor lealdade com a fala ou orientado por um advogado. Monsma diz que inquéritos são mais próximos do conflito no tempo. Não sofrem influência do promotor nem do advogado de defesa. (MONSMA, 2005,p.169). Bretas contribui para a discussão ao escrever que através das mãos dos delegados de polícia, é possível penetrar em residências, bares e locais de trabalho. (BRETAS, 2002, p.11).

\section{A construção da justiça na fronteira oeste}

A construção da burocracia do Estado moderno, segundo a historiografia tradicional, foi um processo de imposição da ordem e do controle da violência contra uma população civil que assistia passivamente as novas configurações sociais e regimes normativos. Adriana Dorfman questiona tais pressupostos ao afirmar que a norma é o compromisso entre estruturas e agências, no caso, o Estado, instituições, o mercado e a população. (DORFMAN, 2012, p.103). Com isso a autora pretende anunciar que as leis não são meras manifestações de um Estado neutro, mas que expressam o complexo caso de interesses entre o público e o privado.

Busco neste trabalho seguir os novos pressupostos que a historiografia recente trouxe sobre a reprodução de normas e construção de sistemas de classificação e leis que foram sendo implementados nos Estados modernos. Segundo Adriana Dorfman, em sociedades complexas como a nossa, o contrato social é debatido permanentemente, sem ruptura com o Estado, a partir de noções locais sobre gênero, classe, faixa etária, etnia, justiça, e comportamentos legítimos ou não. (DORFMAN, 2012. p.103). Me aproprio desta ideia, que faz sentido em ser debatida com outro texto. Salvatore diz que a reprodução das normas e condutas que são essenciais para o funcionamento das sociedades modernas, são fruto de múltiplos produtores de discursos e disciplina. Para o autor, a proletarização não é um produto apenas da relação econômica da expulsão dos trabalhadores dos seus meios de produção. Salvatore defende que as instituições sociais como prisão, hospital, escola têm responsabilidade de construir as identidades individuais e coletivas da sociedade. 
(SALVATORE, 1992. pp. 127-128).

Raúl Fradkin, que analisou os roubos de gado em Buenos Aires na primeira metade do século XIX, traz reflexões importantes sobre o papel da instauração das normas e os casos envolvendo o furto em propriedades. O autor se baseia em E. P. Thompson e Marc Bloch acerca dos costumes e práticas sociais, vê no ordenamento da sociedade a partir da propriedade privada um fator de grande importância para se analisar os roubos de gado. Segundo Fradkin, o código civil que é instaurado em Buenos Aires estabelece um novo princípio: a propriedade sobre os produtos do solo em uma sociedade em que se aceitava os produtos espontâneos do solo para usufruto doméstico. Segundo o autor, com o código civil se pretende acabar com o acesso dos recursos que por costume podiam ser expropriados por amplos setores da população, consagrando assim o regime normativo do acesso através da propriedade privada. Fradkin pondera, no entanto, ao referir que mesmo após o século XIX, é duvidoso que a operação "purificadora" dos costumes rurais tenha tido completo êxito e apagado totalmente a "desordem" do mundo pré capitalista. Para o autor, as "práticas irracionais", normas e valores dos setores sociais subalternos do mundo rural seguem depois do século XIX impregnados pelo costume.

Analisando conflitos nas Minas Gerais do século XVIII, Vellasco defende que historicamente tal imposição é fruto do aumento da capacidade do Estado em negociar seus parâmetros através do sistema jurídico.

\footnotetext{
é forçoso reconhecer que o poder do Estado que se afirmava não podia prescindir, no controle da ordem e na administração dos conflitos sociais, de espaços e margens de negociação. Era nesses espaços que se definiam os limites da obediência e da revolta, que se estabelecia "uma contínua sondagem entre governantes e súditos, a fim de descobrir o que eles podem efetuar impunemente". As situações de domínio necessitavam manter uma base de legitimidade e seus ratios de poder articulados a alguma forma de reciprocidade e negociação com a massa de excluídos das arenas decisórias do Estado, fossem eles os homens livres pobres, os mestiços e negros libertos, ou os setores médios emergentes. (VELLASCO, 2005. p.168).
}

Logo se percebe que o processo de instauração de uma nova ordem não foi uma abstração. Foi materialmente conduzido por negociações entre o incipiente poder público e o poder privado. Nos processos crime do Rio de Janeiro analisados por Chalhoub no início da República, vê-se que a ordem capitalista que surge pretende disciplinar corpos, tempos e locais de trabalho e lazer. O cotidiano policial é visto como ação constante de retirar os "vadios" das ruas e colocá-los em casas de correção para trabalhar, aceitar, acatar a ideologia vigente.

No caso dos roubos de gado, a justiça criminal ainda incipiente começava a buscar 
uma padronização de conduta que envolve o que a autora Maria Aparecida Lopes, que pesquisou o abigeato em Chihuahua no México, chamou de racionalização da economia. Segundo a autora, as transformações vinculadas a mercantilização, também notadas por Farinatti em Alegrete no fim do século XIX, estiveram acompanhadas de um aparato jurídico institucional para regular o comércio e a atividade da criação de gado, como também ligadas a promulgação de leis mais eficazes para punir o roubo de gado.

\section{A criminalização do abigeato em Uruguaiana na passagem para o século $\mathrm{XX}$}

Uruguaiana foi fundada em 1846, emancipando-se do município de Alegrete, que abrangia grande parte dos municípios conhecidos hoje na região oeste do Rio Grande do Sul. Segundo o censo de 1890, a população de Uruguaiana neste ano era de 11.352 pessoas, sendo 5.875 homens e 5.477 mulheres. Dez anos depois, ocorre um aumento da população que, segundo o censo, não é visto em outros municípios da região da mesma forma. A população de Uruguaiana dobra em dez anos, chegando no ano de 1900 a contar com uma população de 23.194 pessoas, sendo 11.580 homens e 11.614 mulheres. Municípios próximos como Alegrete e Quaraí não têm um aumento da densidade demográfica tão acentuado como o de Uruguaiana. Quaraí nestes dez anos tem um aumento da sua população de cerca de 8 mil pessoas para 11 mil, enquanto Alegrete, no mesmo período, tem um aumento de cerca de 16 para 18 mil habitantes.

Joana Medrado ao pesquisar a sociedade do fim do século XIX na Bahia, defende que muitos casos de furtos não chegavam ao poder público devido às desistências por parte dos envolvidos, que resolviam seus conflitos em âmbito privado. Segundo Medrado "provavelmente os fatores de ordem social não apenas influenciavam na decisão de instaurar um inquérito como também importavam mais do que a eficácia de reaver o animal roubado". (MEDRADO, 2008, pp.53-55). Com esta posição a autora defende que certos casos só eram abertos por motivos de reincidência para se buscar uma legitimidade dentro da lei, mas que em outros momentos as divergências poderiam ser resolvidas sem a presença de autoridades.

Encontrei um caso de 1900 em que Daniel, testemunha do caso, relatou que sabia que o réu Mariano era culpado "por conhecê-lo e saber que era gatuno, tendo já sido trazido para a cidade com um couro amarrado no pescoço". ${ }^{2}$ Tal fato me chamou a atenção para a questão da punição que Mariano teria recebido anteriormente. A punição que é mencionada como tendo sido feita em algum momento do passado recente demonstra que ocorreu uma forma

\footnotetext{
${ }^{2}$ APERS. Poder Judiciário. $1^{\circ}$ Cível e Crime. Uruguaiana Processos Crime. Acond: 095.0104 - Est-147-A. n ${ }^{\circ}$ 3186. 1900 .
} 
privada de castigo ao réu, pela qual este foi levado para a cidade com a "marca" de seu crime como uma forma de espetáculo para que quem assistisse, soubesse que era um ladrão de gado ou couro, não passando tal fato pela lógica da polícia e justiça.

Luís Augusto Farinatti estudou a região fronteiriça na segunda metade do século XIX, e ressalta aspectos de modernização da sociedade e transformações que deram nova face ao mundo agrário. $\mathrm{O}$ historiador, que pesquisou a região de Alegrete, município vizinho de Uruguaiana, aponta que a crise do trabalho escravo, a Guerra do Paraguai, a chegada da ferrovia, a difusão dos cercamentos e introdução de novas raças bovinas, são aspectos que devem ser lidos como novidades na região a partir da segunda metade do século XIX. (FARINATTI, 2010, pp. 28-29).

O autor aponta que a constituição de mercado de trabalho e de terras com traços nitidamente capitalistas, com uma centralização administrativa e constituição de um exército, culminam na década de 1870, alguns anos antes do recorte da pesquisa que faço. Tal fato, sugere o autor, diminuiu a possibilidade de pequenos produtores obterem o acesso à terra. Graciela Garcia observou que de 1830 a 1870 caiu o índice de produtores que criavam seu rebanho em terras próprias. Segundo Garcia, o percentual de grandes estancieiros diminui no fim do século XIX, mas a concentração aumentou. Os proprietários com mais de 2 mil reses, eram $38 \%$ na década de 1830 , e detinham $87 \%$ do rebanho. Já na década de 1860 , eles eram somente 15\%, mas possuíam $82 \%$ do rebanho. (GARCIA, 2005. p.25).

O número total de processos crime encontrados sobre roubos de gado no município de Uruguaiana entre 1895 e 1905 foram oito. Estes estavam distribuídos entre os anos de 1899 e 1904. Nos processos é mencionado mais de uma vez que certos réus eram conhecidos como ladrões na região e já haviam sido punidos com um castigo privado e não pelo poder público. Encontrei 12 réus, sendo a ocupação que mais chama a atenção por parte dos réus ser a de jornaleiro, consistindo em 7 dos doze encontrados. O trabalho de jornal envolve uma atividade nas fazendas e estâncias, mas não se caracteriza por uma ocupação fixa e única. $\mathrm{O}$ trabalho poderia ser diário ou sazonal. Mariana T. Flores reflete sobre as ocupações dadas nos depoimentos e sobre como estas podiam ser vividas nas estâncias:

Sabemos que muitas dessas denominações não são definitivas. Sendo a diversificação de atividades outra característica marcante das sociedades pré industriais, muitos desses réus podiam ser aquilo que se autodenominam e também desempenhar outras funções concomitantemente. Em vários dos casos listados, essas múltiplas ocupações ficaram evidentes, como o 'domador e tropeiro', 'serviço de campo e pedreiro', 'criador e negociante' etc. (FLORES, 2014, p.306). 

e-ISSN 2016/Atual: 2525-7870 | e-ISSN 2015/2016: 2447-018X

Edson R. Paniágua defende a hipótese de "à medida que o Estado se consolidava, violência e criminalidade se apresentavam numa única face, ocultando a violência gerada pelo próprio Estado". A partir dessa noção, entendo que a violência gerada pelo Estado tornou-se menos visível, visto que a criminalização de outras violências foram sendo trazidas à tona pela abertura dos processos na justiça. (PANIÁGUA, 2010, pp. 117-118).

O autor defende que a criminalidade, como os roubos de gado e outras formas de delitos, são vistas como resistência pela população da fronteira, acostumada com uma tradição cultural que não reconhecia a nova ordem capitalista.

Tabela 1 - Ocupação do réus

\begin{tabular}{|c|c|}
\hline $\begin{array}{c}\text { OCUPAÇÃO DOS } \\
\text { RÉUS }\end{array}$ & QUANTIDADE \\
\hline Comércio & 2 \\
\hline Cortidor & 1 \\
\hline Jornaleiro & 1 \\
\hline Carreteiro & 1 \\
\hline Agências & 12 réus \\
\hline TOTAL & Creste. \\
\hline
\end{tabular}

Fonte: APERS. Poder Judiciário. Cível e Crime. Processos-Crime. Uruguaiana, 1899-1904.

A tendência de concentração dos rebanhos é uma característica do período, que teve na valorização das terras fator diferencial. Segundo Graciela Garcia, ao longo do século XIX o preço das terras aumentou $800 \%$, enquanto o gado teve seu aumento de $100 \%$. Os dados obtidos por Farinatti e Garcia sobre a população de Alegrete e valorização das terras na região podem contribuir para se pensar na sociedade da fronteira oeste do Rio Grande do Sul no fim do século XIX. Os autores apontam para vinculação entre a propriedade da terra e a possibilidade de criação de gado. Farinatti pesquisou nos inventários da cidade de Alegrete e constatou que todos os proprietários com mais de 2 mil reses eram donos de terras. Já para criadores de porte médio (segundo a escala do autor, de 500 a 2 mil reses), menos da metade eram donos das terras onde o gado era criado. Os índices baixam ainda mais, e para os criadores com menos de 500 reses, o percentual que possuía terra era de $25 \%$. Dos produtores com menos de 100 reses, somente um sexto era proprietário das terras onde o seu gado pastoreava. (FARINATTI, 2010, p.155).

Tabela 2 - Quantidade de animais furtados por processo crime

\begin{tabular}{|c|c|}
\hline PROCESSOS & QUANTIDADE DE \\
\hline
\end{tabular}


RELACult - Revista Latino-Americana de Estudos em Cultura e Sociedade

Revista Latinoamericana de Estudios en Cultura y Sociedad | Latin American Journal of Studies in Culture and Society V. 02, Ed. Especial, dezembro, 2016, p. 617-629| periodicos.claec.org e-ISSN 2016/Atual: 2525-7870 | e-ISSN 2015/2016: 2447-018X

\begin{tabular}{|c|c|}
\hline CRIME & $\begin{array}{c}\text { ANIMAIS } \\
\text { FURTADOS }\end{array}$ \\
\hline Processo 3159 - 1899 & 5 \\
\hline Processo 3186 - 1899 & 1 \\
\hline Processo 3852 - 1899 & 3 \\
\hline Processo 3181 - 1900 & 1 \\
\hline Processo 3201 - 1901 & 1 \\
\hline Processo 1040 - 1903 & 68 \\
\hline Processo 3231 & 1 \\
\hline Processo 3234 & 3 \\
\hline TOTAL & 83 \\
\hline
\end{tabular}

Fonte: APERS. Poder Judiciário. Cível e Crime. Processos-Crime. Uruguaiana, 1899-1904.

Para Farinatti, a leitura dos dados comprova a vinculação entre a propriedade e a possibilidade de criação, mas também demonstra que a sociedade era dinâmica e complexa, com pequenos e médios criadores se fazendo presentes.

A complexidade apontada pelos novos estudos sobre estas duas regiões, na qual o Rio Grande do Sul era a intersecção, não nega as relações de dominação e resistência que marcaram aquelas sociedades. Ao contrário, ao perceber que a acumulação de um ou outro recurso (como a terra ou os escravos) era um instrumento importante, mas não era capaz de propiciar, sozinha, a reiteração de um grupo de elite; ao apontar que os grupos subalternos eram diversificados, tinham demandas e estratégias próprias que informavam suas lutas; enfim, ao elaborar esses procedimentos analíticos, os novos estudos têm conseguido refinar as explicações sobre como se tem operado a perversa química da reprodução de hierarquias sociais, extremamente desiguais, em diferentes contextos. (FARINATTI, 2010, p.155).

Tabela 3 - Quantidade de réus por processo

\begin{tabular}{|c|c|}
\hline $\begin{array}{c}\text { PROCESSOS } \\
\text { CRIME }\end{array}$ & $\begin{array}{c}\text { QUANTIDADE DE } \\
\text { RÉUS }\end{array}$ \\
\hline Processo 3159 - 1899 & 2 \\
\hline Processo 3186 - 1899 & 1 \\
\hline Processo 3852 - 1899 & 1 \\
\hline Processo 3181 - 1900 & 1 \\
\hline Processo 3201 - 1901 & 1 \\
\hline Processo $1040-1903$ & 1 \\
\hline Processo 3231 & 4 \\
\hline Processo 3234 & 12 réus \\
\hline TOTAL & \\
\hline
\end{tabular}

Fonte: APERS. Poder Judiciário. Cível e Crime. Processos-Crime. Uruguaiana, 1899-1904.

Paniágua analisa alguns relatórios dos presidentes de província do Rio Grande do Sul 

e-ISSN 2016/Atual: 2525-7870 | e-ISSN 2015/2016: 2447-018X

e ressalta que nos anos de 1845 e 1847, os crimes particulares, que envolviam ofensas físicas, homicídios, roubos e furtos, eram a grande preocupação dos presidentes de província do Rio Grande do Sul. Tais casos constituíam 90,90\% da totalidade de crimes autuados. No relatório de 1863, Paniágua escreve que o presidente de província chegou a elaborar um mapa específico para Alegrete e Uruguaiana entre os anos de 1853 e 1862, onde predominavam os crimes particulares contra a segurança individual e contra a propriedade. (PANIÁGUA, 2003. pp.124-128).

Ao procurar os relatórios de presidentes do Estado do Rio Grande do Sul, encontrei em 1903 um relato na sessão policial que indica uma repressão aos criminosos e que o aprisionamento deveria estar ligado à valoração do trabalho. Noto que a criminalidade ainda é vista como uma anomalia, dentro de aspectos da patologia social, característica de uma visão da criminologia positivista herdada do século XIX.

\begin{abstract}
A despeito da vastidão do nosso território, a vigilância e a repressão policiais se exercem com inteireza e celeridades notórias, não sendo tolerada a impunidade por mais leve que seja a falta. A ausência dos grandes tipos de criminosos é fato digno de atrair as vistas do observador na investigação das causas da delinquência. Tudo aqui concorre para corrigir as anomalias do caráter e sopitar a eclosão dos maus instintos: o meio físico, a moralidade dos costumes, a índole ordeira e laboriosa da população e, finalmente, os instintos preventivos da nossa legislação processual. (...) Se um bom serviço policial é uma sólida garantia de defesa pública, outras condições são ainda essenciais aos fins que devem preencher a justiça repressiva. Não basta aplicar ao delinquente uma pena restritiva da liberdade durante certo lapso de tempo; é necessário que a sua execução esteja também subordinada a um serviço penitenciário adequado. Sob esse ponto de vista, os aperfeiçoamentos introduzidos na casa de correção a transformaram em estabelecimento modelo. Funcionam ali várias oficinas, onde o trabalho em comum dos funcionários substitui com vantagem a prisão simples ou o isolamento celular. ${ }^{3}$
\end{abstract}

A ideologia do trabalho em combate aos "vadios" e aos criminosos pode ser vista neste relatório de 1903. Porém, os relatórios de Presidentes da Província do Rio Grande do Sul pesquisados dentro dos limites desta pesquisa, não fazem referência ao roubo de gado na fronteira oeste. O fato de não haver reclamações sobre este delito entre os anos de 1899 e 1904 pode ser um indício que o abigeato estivesse sendo menos cometido do que em períodos anteriores mas não há base para se afirmar isso. Esta ausência pode ser um indício para se pensar em uma futura pesquisa. No momento busco interpretar e contextualizar os dados encontrados, onde classifico os roubos de gado como parte do processo de modernização da sociedade de Uruguaiana. A criminalização do roubo onde sete entre doze réus são jornaleiros

\footnotetext{
${ }^{3}$ Relatório do Presidente do Estado Antônio Augusto Borges de Medeiros.1903.pp. 5-6. Disponível em: http://brazil.crl.edu/bsd/bsd/u783/. Acesso em: 15/06/2016.
} 
pode trazer um indício de que os roubos pequenos foram trazidos à tona pelos delegados de polícia. A vinculação entre a propriedade da terra e a criação do gado pode ser analisada a partir destes dados. Os homens que possuíam empregos informais e temporários foram os que mais estiveram à frente dos juízes como réus nos processos de abigeato encontrados.

\section{Considerações finais}

A partir dos dados encontrados e com base na bibliografia pode-se perceber que os delitos encontrados entre os anos de 1899 e 1904 em Uruguaiana envolviam pequenos roubos. O fato de haver poucos réus, não significa que os crimes foram cometidos apenas por uma pessoa. Em alguns processos, houveram ladrões que fugiram no local do crime, e só um foi pego para ser denunciado à justiça. Proponho, a partir da leitura dos processos, apresentar estes roubos como dentro do contexto de modernização da sociedade de Uruguaiana. O município localizado na fronteira oeste passava por transformações ligadas a valorização da terra, do gado, à chegada da ferrovia, introdução de novas raças bovinas e com o regime normativo sendo pautado pela lógica da propriedade privada. Analiso os processos abertos contra os réus do município como dentro do contexto de criminalização, por parte da justiça, de práticas que fugissem à lógica mercantil vinculada ao surgimento do capitalismo na região.

\section{Referências}

BRETAS, Marcos Luiz. O crime na historiografia brasileira: uma revisão da pesquisa recente, $B I B$, n. 32 , p. 49-61, $2^{\circ}$ sem. 1991.

------ As empadas do confeiteiro Imaginário: a pesquisa nos arquivos de justiça criminal e a história da violência no Rio de Janeiro. Acervo. v.15, n.1, 2002.

CHALHOUB, Sidney. Trabalho, lar e botequim: o cotidiano dos trabalhadores no Rio de Janeiro da Belle Époque. São Paulo: Brasiliense, 1986.

DORFMAN, Adriana. Representações, normas e lugares: contos de contrabando da fronteira gaúcha. Para Onde!? (UFRGS), v. 6, p. 102-113, 2012.

FARINATTI, Luís Augusto E. Confins meridionais: famílias de elite e sociedade agrária na Fronteira Sul do Brasil (1825-1865). Santa Maria: Ed. da UFSM. 2010

FAUSTO, Boris. Crime e cotidiano: a criminalidade em São Paulo (1880-1924). São Paulo: Editora Brasiliense, 1984.

FLORES, Mariana Flores da Cunha Thompson. Crimes de fronteira: a criminalidade na fronteira meridional do Brasil (1845-1889). Porto Alegre: EDIPUCRS, 2014.

FRADKIN, Raúl. La experiencia de la justicia: estado, proprietarios y arrendatarios en la 

e-ISSN 2016/Atual: 2525-7870 | e-ISSN 2015/2016: 2447-018X

campaña bonaerense. In: FRADKIN, Raúl. La fuente judicial en la construcción de la memoria. Buenos Aires: Universidad Nacional de Mar del Plata, 1999, p.145-188.

GARCIA, Graciela. O domínio da terra: conflitos e estrutura agrária na Campanha Rio Grandense Oitocentista. Dissertação (Mestrado em História), Universidade Federal do Rio Grande do Sul, Porto Alegre, 2005.

LOPES, Maria Aparecida de S. De costumbres y leyes: abigeato y derechos de propriedad en Chihuahua durante el Porfiriato. México, D.F: El Colegio del México, Centro de Estudios Históricos, 2005.

------. Los patrones de la criminalidad en el estado de Chihuahua: el caso del abigeato en las últimas décadas del siglo XIX. História Mexicana, El Colegio del México, v. 50, n. 3, p. 513553, jan.-mar. 2001.

MAUCH, Cláudia. O processo crime para além dos crimes. XI Mostra de pesquisa do Arquivo Público do Estado do Rio Grande do Sul : produzindo história a partir de fontes primárias. Porto Alegre: CORAG, 2013.238 pp.17-31. Disponível em: <https://arquivopublicors.files.wordpress.com/2014/07/2014-07-16-mostra-depesquisaanais.pdf> . Acesso em: 22/09/2016.

MEDRADO, Joana. “Terra, laço e moirão": relações de trabalho e cultura política na pecuária (Geremoabo, 1880-1900). Dissertação (Mestrado em História) - Universidade Estadual de Campinas (UNICAMP), Campinas, 2008.

Boi fujão ou homem ladrão? Conflitos em torno da posse de animais na região de Geremoabo/BA entre 1880 e 1900.. In: XXIV Simpósio Nacional de História - História e Multidisciplinariedade: territórios e deslocamentos, 2007, São Leopoldo/RGS. Anais do XXIV Simpósio Nacional de História, 2007.

MONSMA. Histórias de violência: Inquéirtos policiais e processos criminais como fontes para o estudo das relações interétnicas. In: Estudos migratórios. DEMARTINI, Zeila DeBrito F.; TRUZZI, Oswaldo Mário Serra. São Carlos. EdUfSCar, 2005.

------. Desrespeito e violência: fazendeiros de café e trabalhadores negros no Oeste paulista, 1887-1914. Anos 90. v. 12, n. 21, 2005.

PANIÁGUA, Edson Romário Monteiro. Fronteiras, violência e criminalidade na região platina: o caso do município de Alegrete (1852-1864). Dissertação (Mestrado em História) Universidade do Vale do Rio dos Sinos (UNISINOS), São Leopoldo, 2003.

REIS, João José. Rebelião escrava no Brasil: a história do levante dos Malês. São Paulo: Brasiliense, 1986.

REVEL, Jacques (org.). Jogos de escalas: a experiência da microanálise. Tradução Dora Rocha. Rio de Janeiro. Editora Fundação Getúlio Vargas, 1998.

SALVATORE, Ricardo D. Reclutamiento militar, disciplinamiento y proletarización en la Era de Rosas. Boletin del instituto de Historia Argentina y Americana. "Dr E. Ravignani". Tercera Serie, num. 5, $1^{\circ}$ semestre de 1992. 

e-ISSN 2016/Atual: 2525-7870 | e-ISSN 2015/2016: 2447-018X

VELLASCO, Ivan de Andrade. Os predicados da ordem: os usos sociais da justiça nas Minas Gerais 1780-1840. Revista Brasileira de História. Vol.25 n .50 São Paulo, Julho/Dezembro, 2005 . 